\title{
General Anthropology
}

Disease

\section{An Unnatural History of Emerging Infections}

\section{By Ron Barrett}

Macalester College

George Armelagos

Emory University

Editor's Note: This article is excerpted with minimal changes by the authors from the first chapter of An Unnatural History of Emerging Infections published by Oxford University Press: 2013.

$\mathrm{M}$ icrobes are the ultimate critics of modernity. ${ }^{1}$ Devoid of thought and culture, they can nevertheless adapt to our latest technologies by the simple means of genetic mutation and rapid reproduction. Bacteria, viruses, and other microparasites have evolved to operate in almost any human environment: in our ovens and refrigerators, in our heating vents and air-conditioning ducts. Some thrive in the industrial excrement of our oil spills, car

Disease continued on page 2

\section{In This Issue}

Barrett and Armelagos Page 1 on

Emerging Diseases

Fuller and Murphy on Page 1 Indian Agriculture

Dunn on Page 1

Finding References

Paleoanthropology Page 11

Useful Ethnographies

\section{Plant Domestication}

\section{Overlooked But Not Forgotten: India As A Center for Agricultural Domestication}

\section{By Dorian Q. Fuller and Charlene Murphy \\ Institute of Archaeology, University College London}

$\mathrm{W}$ hen the general public thinks of the origins of agriculture they often think of V.G. Childe's (1923) Neolithic Revolution, the Fertile Crescent, and the spread to the West of a few select cereal crops and to the East, with separate origins only in China (a story popularized by writers such as Jared Diamond (1997) and Ian Morris (2010). They do not often think of the subcontinent of India, but this needs to change. Like several other parts of the world, recent and growing archaeological evidence combined with better botanical documentation of wild crop ancestors, suggests that there were at least 19 primary centers of crop domestication (Larson et al. 2014). This includes at least three areas of South Asia (comprising primarily the subHimalayan countries of Bangladesh, India, Sri Lanka, and Pakistan), although as we suggest below we should consider 5 regions of South Asia. Thus, archaeobotanical research on these overlooked centers of domestication is contributing to a growing global awareness of a new paradigm of "protraction and entangled processes" in the origins of agriculture (Fuller 2010).

India possesses a unique Neolithic transition that has shaped the cultural and ecological trajectory of the subcontinent. Regions of the world that have long been recognized as independent centers of agricultural origins and early civilization include (1) the well-known sedentary cereal cultivators

Indian agriculture continued on page 5

\section{Teaching Strategy}

\section{Teaching Scholarship to Undergraduate Students}

\section{By Janet $S$. Dunn}

University of Michigan-Dearborn

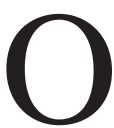
ne of the ironies of the digital infor mation age is that while increasing amounts of information are available to wide audiences, traditional scholarly publications, such as academic journals, are less apparent to students. The content of most scholarly journals is now available electronically, and is accessible 24/7 in remote locations and on a variety of devices. Yet, to those who are unfamiliar with the concept and content of academic journals, the movement of scholarly publishing to electronic formats, along with the removal of many hard-copy versions of journals from university libraries, has made these journals "invisible" to the average student, even as access to electronic journals has increased substantially.

At the same time that traditional academic publications are becoming more virtual, many undergraduate students lack direct experience with scholarly output. Few undergraduate students understand the scope of scholarly journals, and even fewer have purposely sought out information from specific journals. Although many students have a general sense that journal articles are sources of new (or curated) research results, few are adept at locating specific information from these sources. Thus, when confronted with a research assignment, many academically inexperienced students choose the seemingly simpler option of doing a Google search (or a somewhat more eruditesounding "Google Scholar" search), which frequently produces tangible (though limited) results, generally resulting in students

Citations continued on page 8 
Morris, Ian

2010. Why the West Rules- For Now. The Patterns of History and what they reveal about the future. London: Profile Books

Patel, A. K.

2008. New radiocarbon determinations from Loteshwar and their implications for understanding Holocene settlement and subsistence in North Gujarat and adjoining areas. In South Asian Archaeology 1999. E.R. Raven, ed. Pp 123-1. Groningen, Netherlands: Forsten.

Sharma, G. R., Misra, V. D., Mandal, D., Misra, B. B., \& Pal, J. N.

1980 Beginnings of Agriculture (EpiPalaeolithic to Neolithic: Excavations at Chopani-Mando, Mahadaha, and Mahagara). Allahabad: Abinash Prakashan.

Smith, Bruce D.

2001 "Low-Level Food Production". Journal of Archaeological Research 9(1):143.

Southworth, Franklin C.

2005 Linguistic archaeology of South Asia. London : Routledge Curzon 2005

Tewari, R., R. K. Srivastava, K.S. Saraswat, I.B. Singh, and K.K. Singh

2008 "Early Farming at Lahuradewa." Pragdhara 18: 347-73.

Weber, Steve

2003 “Archaeobotany at Harappa: Indications for Change." In Indus Ethnobiology: New Perspectives from the Field, pp. 17598. Maryland: Lexington Books.

Weber, Steve, and Arunima Kashyap 2013 "The Vanishing Millets of the Indus Civilization." Archaeological and Anthropological Sciences.
Citations continued from page 1

feeling satisfied with the outcome of their searches while remaining ignorant of the wealth of information available in the vast array of academic journals.

What otherwise technology-savvy college students seem to lack is a clear understanding of where scholarly results reside, how they are disseminated, and how they can be retrieved, evaluated, and used by scholars and others. Because academic journals have been at the forefront of the digitization of their content, and because in many disciplines journal articles are the primary means of scholarly communication, digital competency for college students should include a thorough understanding of what journals are, what type of information is contained in them, and how this information can be accessed. Linking this understanding to instruction in the use of citations and references-both to identify the sources used in academic publications and to avoid the pitfalls of plagiarism - further emphasizes the importance of being able to identify, locate, and use scholarly sources in the digital age.

Students' lack of familiarity with scholarly material and with the conventions for citing sources present a challenge to instructors in courses that aim to engage students with academic writing. Many resources exist for presenting this material to students, including traditional writing handbooks such as The Little, Brown Compact Handbook (Aaron 2012), web sites such as Purdue University's Online Writing Lab (Purdue OWL 2014), and librarian-led instruction for students at many colleges and universities. In spite of the availability of these resources, I find that students need hands-on experience in finding, reading, using, and citing academic works in order to become comfortable and adept in the use of scholarly sources.

This article describes a teaching strategy that engages undergraduate students with peer-reviewed journals while illustrating the use of citations and references. A key feature of this strategy involves the use of a Reference Style Guide worksheet by students to collect examples of particular types of references (e.g., a single-authored article, an edited volume, etc.). Using paper or electronic copies of American Anthropologist (or any other easily sourced journal), students find examples of various types of publications in the reference sections of published articles. The completed worksheet is then used by each student in all researched writing assignments as a personal style guide for the formatting of references according to the American Anthropological Association style (AAA 2009).

\section{Learning about Peer-Reviewed Journals}

R efore beginning the worksheet exercise, I provide an overview of academic journals, explaining the general concept of peer review and the difference between popular magazines and peer-reviewed journals. I describe what peer review is, how the process works for journal articles, and how the prepublication review of journal articles differs from other, more familiar types of reviews, such as book reviews and product reviews. Here, I find it useful to provide a visual contrast between a traditional peerreviewed journal (such as Science) and a high-quality popular magazine (such as Scientific American or Natural History, whose articles many students have read). Such a contrast demonstrates the difference in the content of each type of publication, and can be used to illustrate the scope and intended audience of each periodical. Since many students have difficulty determining whether particular journals are peer-reviewed, this contrast also emphasizes the need to look beyond the title (or cover) of a publication for information about its status as a scholarly journal or popular magazine.

Following the general discussion of peer review, I then illustrate the "look and feel" of various peer-reviewed journals, showing examples from the many subdisciplines of anthropology as well as selected journals from other fields. I like to include hard-copy versions of journals in this presentation in order to emphasize the formats of physical journals - formats that are familiar and logical in printed journals but less evident when viewed only in electronic format. To further make the connection between the printed and digital versions of the journal, it is useful - if the classroom is Internetconnected-to browse the electronic version of the same journal issue, pointing out the various parts of the journal (such as the front matter, table of contents, articles, and other content) and demonstrating how these 
parts can be accessed. Whether looking at printed or electronic versions of the journal, I use this opportunity to point out the location of critical identifying information for each journal (i.e., the title of the journal, the volume and issue numbers, and the page numbers for each article), since this information is essential for locating and referencing the content of peer-reviewed journals.

\section{Learning about Citations and References}

$\mathrm{F}$ ollowing this overview of peer review and tour through one or more journal issues, I examine several articles in an anthropology journal, pointing out the use of citations and references in the articles. While this information seems intuitive and commonsense from the instructor's perspective, a surprising proportion of upper-level students have had little or no experience reading works that utilize in-text citations, and thus they are unsure of what this parenthetical information means and how they can use it.

I use examples from articles (projected on a screen by whatever technology is available) to show the direct correspondence between the in-text citations and the references listed at the end of the article. Here I point out the use of in-text citations throughout the text and the format of these citations, including examples of single- and multiauthored works, multiple publications by the same author (in the same year and in multiple years), and publications authored by institutions. I also point out the inclusion of page numbers in the citations for quoted material as well as the standard format for citing several different works in one parenthetical list of citations, since these details have confounded many students in their previous written work.

Next, I move to the references section of the article, pointing out the overall format of the alphabetical list of references and the particular features of the AAA style for references (AAA 2009). In the references section, I identify various types of publications, including journal articles, books, chapters in edited volumes, reports, dissertations, web sites, and conference presentations. Since many of the writing assignments in my courses involve finding journal articles, I also make a point of showing how one can differentiate a journal article from a book (or book chapter) in a list of references by paying close attention to the information presented in the reference.

At this point-since student interest often wanes with a heavy focus on small details-I like to move beyond the article being examined and locate several of the publications included in the article's list of references. If the classroom is Internet-connected, students can identify several journal articles to look up, and the classroom computer (or students' own devices) can be used to locate these works through the university's online library collections. If realtime library searches are not possible in the classroom, a simulation of the process can be devised by preselecting several works from the list of references, locating copies of these works before the class presentation, and projecting images of the selected works, along with information about the steps involved in locating the works.

Whether the examples are selected during class by students or pre-selected by the instructor, this demonstration of how to locate specific publications from an article's list of references makes a tangible connection between the scholarly article and the sources used in the article. It also reinforces for students the steps involved in finding particular articles in a given journal, steps they can later follow in their own research projects.

\section{Learning a Reference Style}

A fter presenting an overview of peer re viewed journals and the mechanics of citations and references, I begin the exercise involving the Reference Style Guide worksheet (see Figures 1 and 2). This exercise-during which groups of students scour journal articles for examples of particular types of references-usually takes one class period, though it can be continued outside of class by individuals or groups. At the completion of the exercise, students will have created a personal style guide for the formatting of references, using examples from a standard anthropological journal. Students then use this style guide when preparing their own written work later in the term.

For this exercise, I like to use paper copies of American Anthropologist so that stu- dents become familiar with the look and feel of anthropology's flagship journal. However, other titles-or electronic version of journals - can be used for the exercise. What is important is to have students find examples of various types of scholarly publications in the references section of a typical journal article and to copy each correctly formatted reference so that these examples can be used as guides in later writing projects.

To complete the exercise, I have students work in groups of three to five individuals, and I give each group an issue of American Anthropologist, instructing them to find examples of ten different types of publications in the references of one or more articles in their journal issue. The publication types include the kinds of references they are likely to encounter when researching topics related to the course; these are: (1) a book with a single author, (2) a book with multiple authors, (3) an edited volume (with the editor[s] listed as the "author"), (4) a chapter in an edited book, (5) a journal article with multiple authors, (6) a journal article with a single author, (7) a paper presented at a conference, (8) a thesis or dissertation, (9) a publication with an institution given as the author, and (10) an electronic/ online source.

Each student in the group also receives a double-sided worksheet (Figures 1 and 2) that lists the ten publication types and that has space for inserting two examples of each type of reference. The right margin of the worksheet also has a place to indicate the volume, issue, and page numbers where each example reference was found, allowing students (or the instructor) to locate the original information at a later time, if needed.

Although using only one copy of a journal for a group of several students can seem awkward, the group nature of this exercise helps to involve students of all experience levels. In most of these small groups, one or two students have facility with the project, while one or two others are initially lost. By working together to find examples of various publication types, all members of the group usually succeed in compiling at least one illustration of each type of reference found in the pages of the journal. And by writing out (in the correct format) example references for various types of publications, each student is forced to pay close atten- 
tion to the components of the reference and the formatting of these components in a reference list.

One useful variation of this exercise is to have half of the groups work on only the odd-numbered publication types on the worksheet while the other half work on the even-numbered types. Then, after each group has completed its assigned reference types, a representative of each group writes out for the class (on the blackboard/ whiteboard or on a projected device) an example of one of the types of references found by the group. When all of the examples have been displayed (and conceptual errors or misunderstandings have been noted and corrected), students can also copy these new examples onto their worksheets, thereby ensuring that they have at least one illustration of each type of reference. In this way, students can benefit from the diligent inclass work of their classmates, especially in the illustration of the more uncommon types of references, such as theses and works authored by institutions.
Another variation involves completing only a few examples in class and having students work on the remaining examples outside of class. In addition, the completed student worksheets can be compiled, posted on a course site, or collected and reviewed by the instructor. In my classes, I like to have students retain their worksheet until the completion of their final papers, instructing them to use their personal Reference Style Guide to ensure that the list of references in their own written work is complete and accurate. In this way, the worksheet serves as a resource for each student throughout the term, and the repeated reference to the information contained in it reinforces the lessons learned during the in-class exercise.

The end result of this teaching strategy is that students learn to recognize various types of publications, and, together with an understanding of the scope of scholarly journals as well as a grounding in how to locate particular journals and their content, they are better able to find, use, and cite scholarly works in their own writing projects. The experience of handling academic journals and using these journals to pull out detailed information from lists of references familiarizes students with scholarly works while engaging them with the mechanics of using the AAA reference style.

\section{References}

Aaron, Jane E.

2012 The Little, Brown Compact Handbook. 8th edition. Boston: Pearson Higher Education.

American Anthropological Association (AAA)

2009 AAA Style Guide. http:// w w w . a a a n t. org/public a tion s/ style_guide.pdf, accessed June 3, 2014.

Purdue Online Writing Lab (OWL)

2014 Online Writing Lab. https:// owl.english.purdue.edu/owl/, accessed June 3,2014.

Figure 1. Reference Style Worksheets
Reference Style Guide

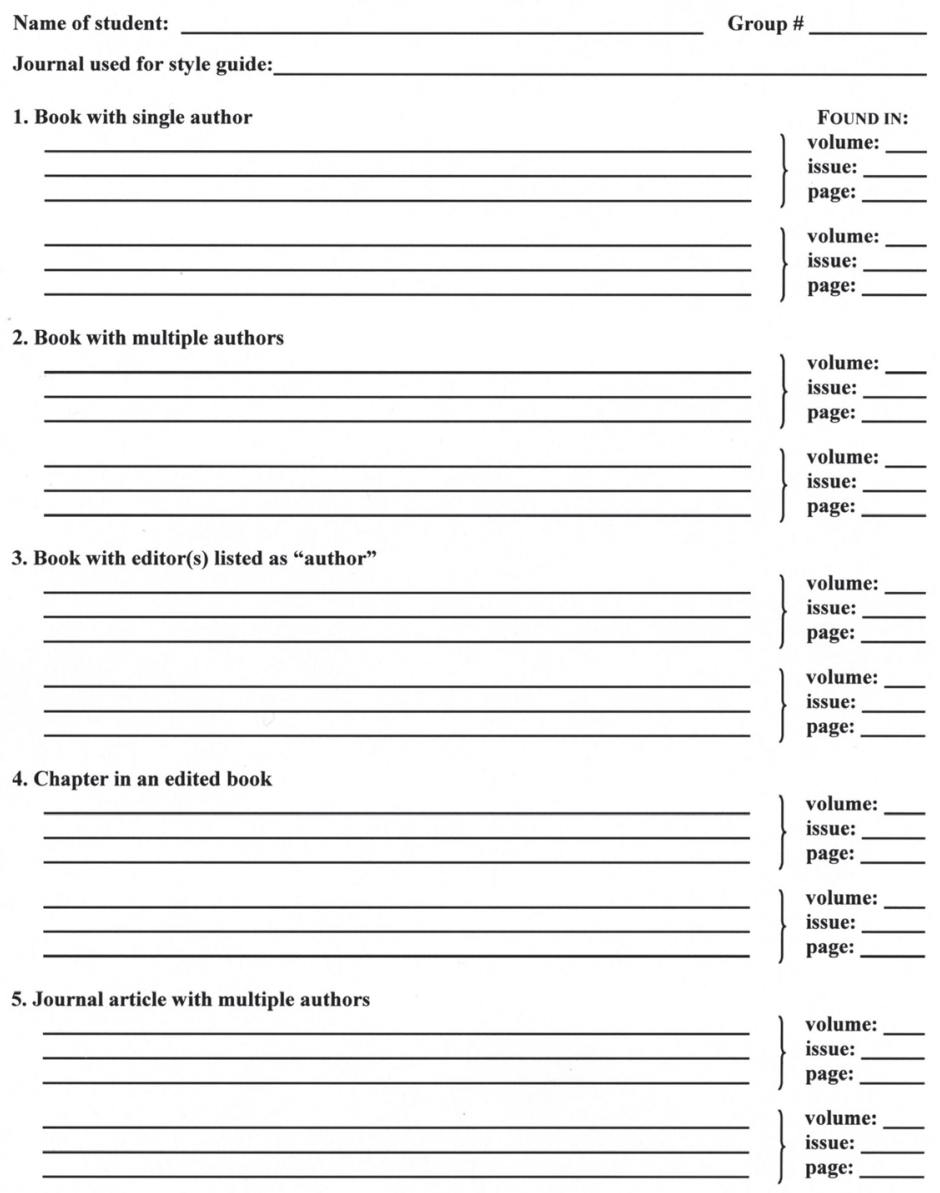

Reference Style Guide - continued

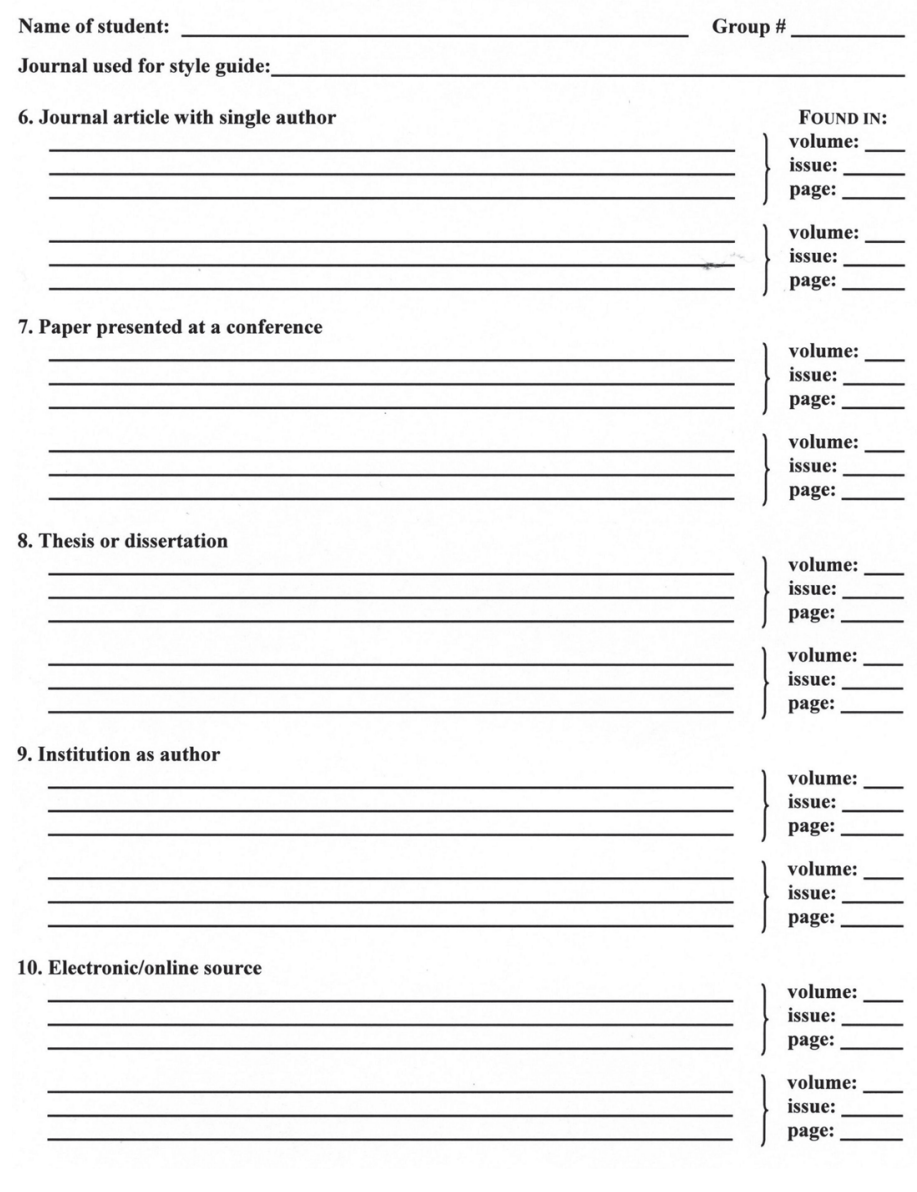

